\title{
Development of A Segmented - Screw Type Expeller for Production of Virgin Coconut Oil
}

\section{T B Adhikarinayake}

\begin{abstract}
A continuous type expeller, which is presently pending a patent, was developed to extract virgin quality coconut oil. Segmented-screw helical ribs with stationary pegs fitted to the screw barrel facilitate forward movement of material without clogging and generating heat. A movable pressure cone fitted at the discharge end provides sufficient pressure inside the screw barrel.
\end{abstract}

Optimum performance of the expeller was at 33.6 RPM of the screw shaft and 10-12 liters of virgin coconut oil in an hour with a $60 \%$ oil yield was realised. Sieve analysis of press cake showed that the material was subjected to extensive shearing while compressing, which leads to high oil recovery. Power requirement was $1.38 \mathrm{~kW}$.

Since the expeller is operated by a single-phase $2 \mathrm{HP}$ motor, it can be used to produce virgin quality coconut oil at cottage level as a self employment. Due to simplicity of the expeller, it can be fabricated in a medium level workshop.

Key words: coconut oil, expeller

\section{Introduction}

Coconut oil (CNO) is one of the important food commodities used for food preparation and for various other applications. CNO is a major kernel product next to desiccated coconut (DC). In 2005, 2576 million nuts were harvested and 2000 million tons of CNO and 36991 tons of DC were produced (Anon, 2005). Coconut oil has been used in ayurveda for various medicinal oil productions and skin ailments. CNO contains about $65 \%$ of short and medium chain fatty acids, which do not contribute to the synthesis of cholesterol in metabolism (Peiris, 2005). Approximately $50 \%$ of the fatty acids in coconut fat are lauric acid and it is a medium chain fatty acid, which has an additional beneficial function of being formed into monolourin within the human body (Enig, 1996). Therefore, it is easy to digest and $\mathrm{CNO}$ has the least amount of cholesterol of 0-14 ppm compared to other oils such as palm oil (18 ppm), soy oil (28 ppm), corn oil $(50 \mathrm{ppm})$ and butter (3150 ppm) and is a good source of instant energy. Also, CNO has anti-virus, anti-bacterial and anti- fungal properties (Enig, 1996). Therefore, CNO fetches a superior position among the other edible oils.

Usually, CNO is produced from copra and copra oil extraction requires large-scale high pressure, energy intensive equipment and experience. Unhygienic copra means that the resultant oil is normally of low quality with a Free Fatty Acid (FFA) level of $3 \%$ or more. Therefore, various quality improvements like, refining, bleaching and deodorizing are required to convert $\mathrm{CNO}$ into a commercially acceptable product. Due to high pressure in the expeller and friction against the metal parts, generation of heat is unavoidable and therefore, most of the nutrients are destroyed and also due to the caramalization of sugar and protein, oil has a yellowish colour.

Hitton \& Ethering, 1997 have introduced a process of direct micro expelling (DME), in which fresh grated coconut is dried to $10 \%-12 \%$ (wb) moisture content, packed into a cylinder and heated in an over to $60-80^{\circ} \mathrm{C}$ for about 30 min. The cylinder is then placed in a press and oil is extracted by applying sufficient pressure for 10 minutes. NERD Centre has developed a similar method of drying grated coconut in the sun for 2 hrs, until oil is visible when the coconut is pressed between thumb and forefinger (moisture is $10 \% \mathrm{wb}$ ). Then it is pressed in a specially modified string hopper mould (Ranatunge, 2000).

Eng. (Dr.) T.B.Adhikarinayake, PhD, MEng, MSi MIE(SL), MIAgrE(UK),CEng(UK). Deputy General Manager(Services), Head) Agriculture \& Post Ilarest TechonologyDivision, NERD Centre of Sri Lanka. 
The extracted oil is a transparent liquid with high quality, conforming to virgin quality standards. Since this mould has the holding capacity of a nut, the capacity of the mould was increased to about $3-4$ nuts and now it is popular as a cottage industry. The third version of this type has a 10 - 12 nuts holing capacity press in which partially dried coconut is pressed by a hydraulic jack (Santha, 2001).

The above three presses are used on batch operation and have limited oil extraction capacities. Since there is a great demand for coconut oil of virgin quality in local and export market, it creates a requirement for a large-scale extractor. This study aims at investigating and exploring the possibility of designing and fabrication of a continuous type expeller which can extract oil from grated coconut without generating heat to produce virgin quality coconut oil.

\section{Design and constructional features of the expeller}

In the past, screw type extruders were designed to transport viscous polymers. Nowadays, the extrusion process is applicable to other types of materials such as human food, pet food and biomass. The design of the screw extruder is challenging as a great number of variables affect the quality of the product and also, the purpose of the extruder. Therefore, a trial-and-error approach was applied for the extruder designs. Dabriel et al, 2001 and Fekete et al, 2004 have attempted to develop some models and further investigations are needed.

Screw type extractors / presses are extensively used in oil extraction as they can be used to twist and compress the material. There are basically five types of screw shafts used in the industry for various purposes.

- Screw shaft with uniform diameter and pitch

- Screw shaft with increasing diameter and uniformpitch

- Screw shaft with decreasing pitch

- Tapered screw with cylinder

- Combination of above

Usually the screw shaft with uniform pitch is used to transport material within a short distance. In the coconut oil industry, a screw shaft with increasing diameter is employed to extract oil from copra. Past studies showed that this expeller is not suitable to extract oil from partially dried grated coconut due to the small particle size of the feed. These expellers are designed to extract oil from granular type particles like seeds, as the volume reduction of material in squeezing is replaced by the intergranular space and also, for particles which are not sticky at the feeding point. The major difficulty in this press with grated coconut is that the feeding material is rotating with the screw shaft and building up in the space, converting the screw into a solid shaft. Usually, the material has to be moved in a longitudinal direction without rotating with the screw. To achieve this, the barrel provides longitudinal bars to avoid rotation and these elements provide the necessary tangential friction to produce the pushing effect of the screw. In the noodles making industry, twin-screw extractors are used to avoid any building up of paste and also to achieve self-cleaning of the screw.

Several preliminary tests have been conducted with available screw presses and two basic problems were identified. The first problem was the bridging of grated coconut over the screw shaft and the second was not conveying the material through the barrel.

\section{Feeding hopper}

The bottom of the hopper has to be designed to avoid any bridging of material just over the screw. Therefore, the section just over the screw was widened in order to drop the material on to the wider exposed screw as shown in Figures 1 and 2 .

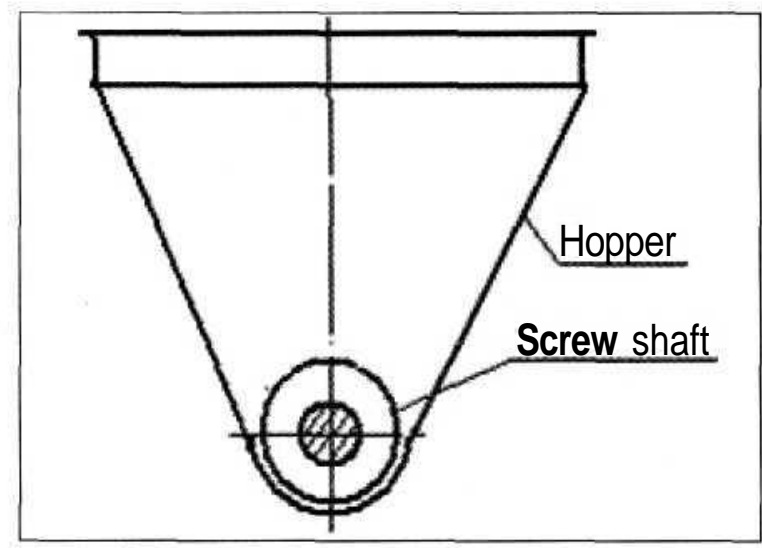

Figure 1. Feeding hopper with wide bottom 


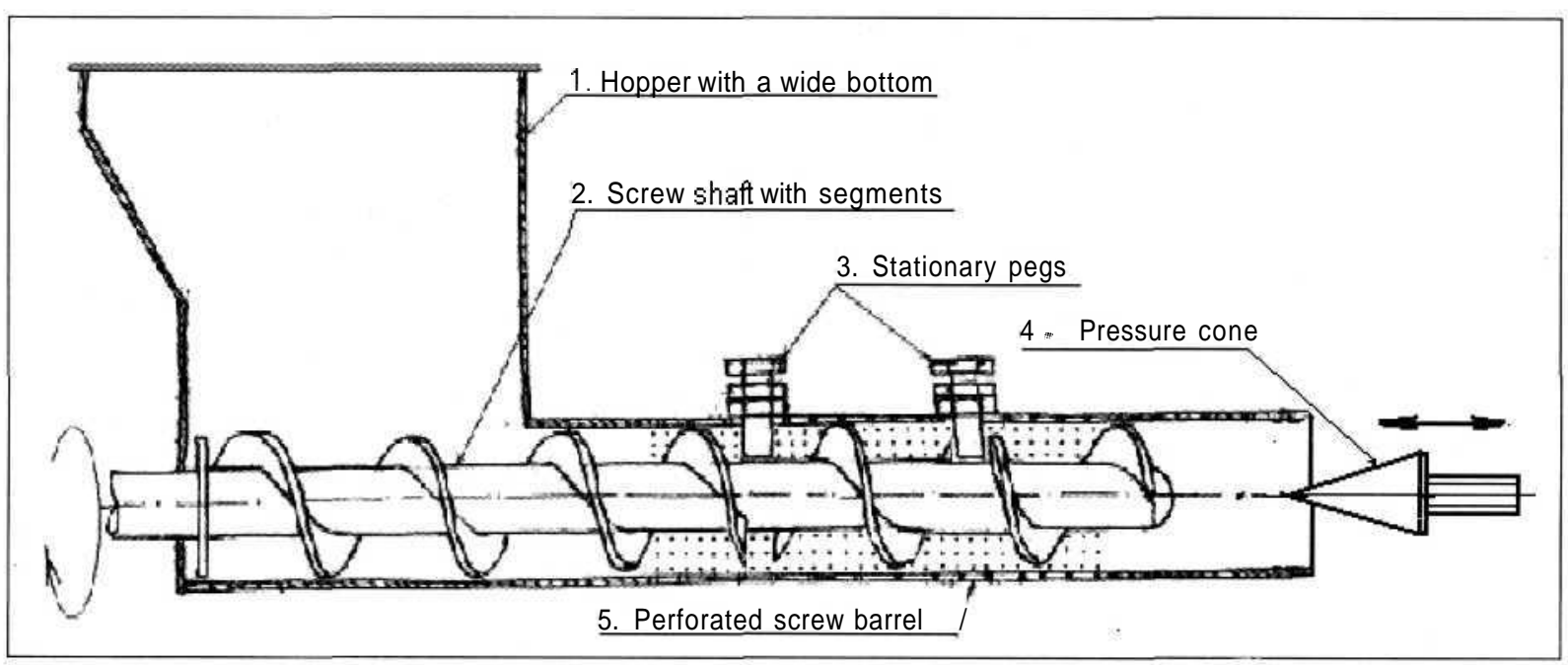

Figure 2. Conceptual design of the screw type virgin coconut oil expeller

\section{Screw shaft and screw barrel}

A screw shaft with a uniform pitch is easy to fabricate than the other types. In order to avoid building up of material within the screw rib space by rotating it with the screw, a few pegs are welded to the barrel as shown in Figure 2.

The special features of the proposed expeller is that the screw shaft is made in segments leaving space to pass the stationary pegs, which are fitted to the barrel and these pegs act as obstacles to prevent rotating the material with the screw shaft. This arrangement is a new concept and it is easy to fabricate compared to the other screws of variable pitch, increasing diameters and twin screw. The pressure inside the barrel is created by adjusting the pressure cone or using a die head fitted to the barrel.

\section{Experimental procedure}

\section{Sample preparation}

Matured coconut was grated and dried in the sun to the required moisture levels. Moisture content was determined by the infra-red moisture analyzer MX 50 of accuracy $\pm 0.01 \%$. Preliminary testing was carried out by the expeller with samples dried to differentlevels to determine the optimum moisture content of the sample for the expeller to be tested.

\section{Testing of the expeller}

The performance of the expeller was evaluated at different revolutions of the screw shaft by changing the sprocket wheels purchased in the market. Input capacity of raw material and oil yield were measured by operating the expeller for a known period with samples dried to predetermined levels. Optimum revolution was selected considering the input capacity and oil yield. Temperatures at the screw barrel and of oil samples were measured using a digital thermometer Digitron 2000T of accuracy $\pm 0.1{ }^{\circ} \mathrm{C}$.

\section{Analysis of oil samples}

The extracted oil was analyzed for quality parameters of free fatty acid (FFA), iodine value, colour, and moisture content. Analysis was carried out at the laboratory of the Coconut Research Institute, Lunuwila as facilities to analyze some parameters were not available at the NERD Centre.

\section{Analysis of press cake}

Press cake was analyzed for residual oil content by the distillation method. Also, the cake was subjected to sieve analysis. Electromagnetic sieve shaker CISA RP08 having sieves of aperture size 10, 20, 30, 50 and 100 micrometers with intermittent tapping was used for sieve analysis. Samples of $100 \mathrm{~g}$ were weighed to the nearest $0.1 \mathrm{~g}$ and sieving was carried out for 10 minutes.

Experimental data were subjected to analysis of variance (ANOVA) procedure using SAS (SAS system for window 98) package. Treatment means were compared at $\mathrm{P}<0.05$ level accuracy to the Duncan's New Multiple Range Test (DNMRT). 


\section{Results and Discussions}

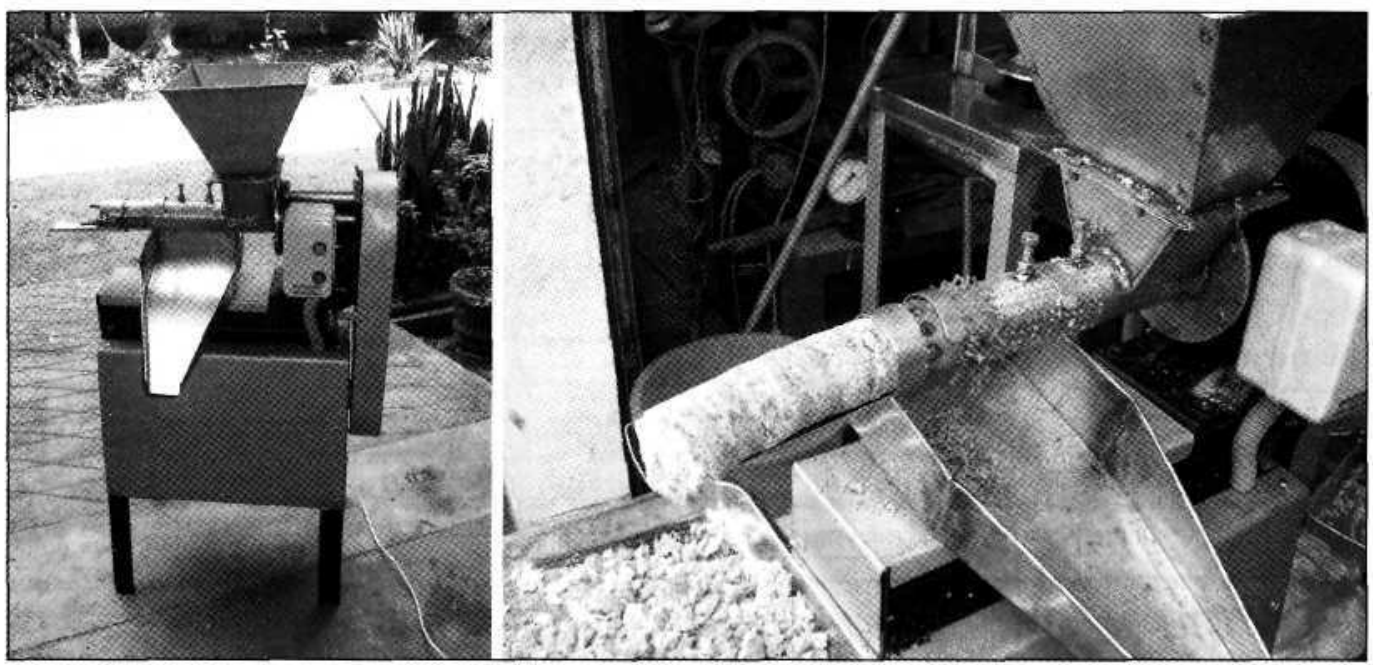

Figure 3. View of the segmented-screw type oil expeller

Figure 3 shows the external view of the expeller and a close view of the screw barrel.

\section{Moisture content of feed}

According to previous studies the grated coconut has to be dried to a moisture content of $10 \%$ to produce oil of virgin quality and therefore, initially, the expeller was tested with similar quality coconut gratings, but the extracted oil appeared to be of a creamy colour due to high water content and it was still an emulsion of oil with water. Hence, the expeller was tested with coconut gratings dried to different moisture levels. The optimum moisture level was from $3 \%$ to $5 \%$. Below $3 \%$, oil recovery is very low as it was similar to desiccated coconut.

\section{Optimum revolutions of the screw shaft}

Revolution of the expeller shaft was varied by changing the RPM of the screw shaftfrom 6 to 75

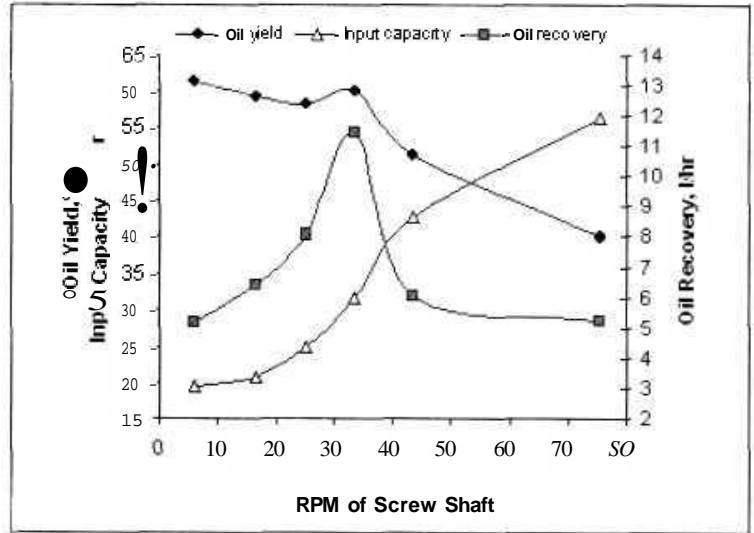

Figure 4. Relationship between RPM of screw shaft with oil yield, input capacity and oil yield
RPM by fixing different, driving and driven sprocket wheels. Figure 4. shows the oil yield, oil recovery and input capacity at different RPMs of the screw shaft of $6.1,16.5,25.2,33.6,43.6$ and 75.5 .

When the RPM of the screw shaft was increased, the input capacity was also increased due to the increasing feed rate but oil yield showed a gradually decreasing trend. However, it is clearly noticed that oil recovery increased up to 33.6 RPM and beyond that it reduced sharply.

Table 1 shows that the highest oil yield was given at 6.1 RPM, but the oil recovery was $5.2 \mathrm{l} /$ hr. However, at 16.5, 25.2 and 33.6 RPMs, no significant difference was shown in oil yield. Therefore the optimum RPM of the screw shaft was selected as 33.6 .

\section{Sieve analysis of press cake}

Figure 5, shows distribution of particles of fresh coconut and press cake after oil extraction by sieve analysis. It clearly indicates that fresh coconut is subjected to size reduction while oil is extracted and it helps to rupture the oil cells. Maximum particle size of fresh coconut sample contains $60 \%$ of 20 -micrometer size and gradually it reduced to $30 \%$ of 30 -micrometer size and ended up with at $1.2 \%$ of 50 micrometer size particles.

Figure 5 shows that, the peak of particle distribution curves moved towards the right side when the RPM of the screw increased. At the lowest RPM of 6.1 the sample contains $40 \%$ of 30 -micrometer size and $20 \%$ of 50 -micrometer size particles. 
Table 1. Moisture content and relationship between RPM of screw shaft with oil recovery, input capacity and oil capacity

\begin{tabular}{|c|c|c|c|c|c|c|c|}
\hline \multirow[t]{2}{*}{ RPM } & \multirow{2}{*}{$\begin{array}{c}\text { Oil yield } \\
\%\end{array}$} & \multirow{2}{*}{$\begin{array}{c}\text { Oil recovery } \\
\text { 1/hr }\end{array}$} & \multirow{2}{*}{$\begin{array}{l}\text { Input } \\
\text { capacity } \\
\text { kg/hr }\end{array}$} & \multicolumn{4}{|c|}{ Moisture content, \% } \\
\hline & & & & Fresh & Dried & Cake & Oil \\
\hline 6.1 & $61.5 a^{a^{*}}$ & $5.2 \mathrm{a}^{*}$ & $19.5^{a^{*}}$ & & 4.1 & 8.12 & \\
\hline 16.5 & $59.3^{\mathrm{b}}$ & $6.4^{b}$ & $20.8^{\mathrm{b}}$ & & 4.1 & 7.69 & \\
\hline 25.2 & $58.3^{b}$ & $8.0^{c}$ & $24.8^{c}$ & & 3.9 & 8.17 & \\
\hline 33.6 & $60.0^{b}$ & $11.4^{\mathrm{d}}$ & $31.6^{\mathrm{d}}$ & 47.3 & 4.0 & 8.38 & 0.61 \\
\hline 43.6 & $51.2^{c}$ & $6.1^{b}$ & $42.7^{\mathrm{e}}$ & & 4.4 & 7.51 & \\
\hline 75.5 & $40.1^{d}$ & $5.2^{\circ}$ & $56.3^{t}$ & & 4.5 & 7.89 & \\
\hline
\end{tabular}

• ' Values with same letters in the column are not significantly deferent ap=0.05

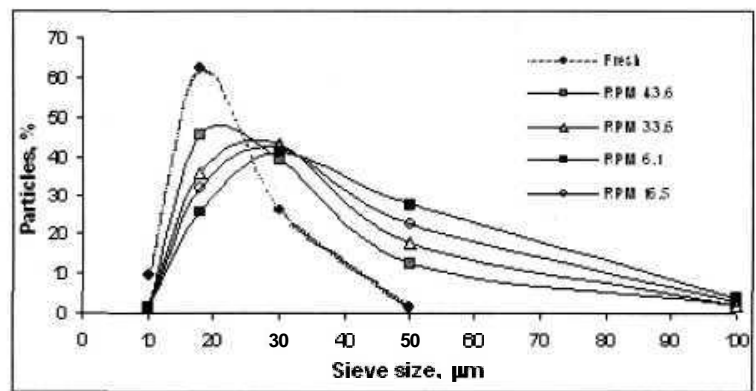

Figure 5. Sieve analysis of input coconut and press cake after oil extraction

\section{Quality analysis of oil}

Oil extracted from partially dried grated coconut by the expeller at the laboratory test as well as in the field evaluation was analyzed for its quality by the Coconut Research Institute, Lunuwila and results are shown in Table 2.

Both oil samples conformed to the virgin coconut oil quality standards. Free fatty acid (FFA) values of both oil samples were very much bellow 0.2 and values are 0.04 and 0.05 respectively. Colour of oil also was very much lower than SLS standards and it looked like water. However, other parameters were not measured due to lack of chemicals at the CR1.

\section{Field evaluation of the expeller}

The expeller was given to a small-scale virgin CNO producer who had previously used a hydraulic jack operated press and he agreed at once to use this expeller for convenience.

Figure 6 shows the results of the field evaluation. The maximum oil recovery of the expeller was $13 \mathrm{~kg} / \mathrm{hr}$ and the minimum was 9.2 $\mathrm{kg} / \mathrm{hr}$. Oil yield varied from 55 to $60 \%$ based on the input material of $4 \% \mathrm{MC}(\mathrm{wb})$.

The performance of the expeller was evaluated for over four months by the oil producer and the expeller was subjected to the endurance test. It was found that a few cracks at the screw barrel flange which was fitted to the bearing housing had developed and also observed an eccentric movement of the cake discharge end due to high pressure, therefore, the free end of the screw barrel was fixed to the frame for steady operation.

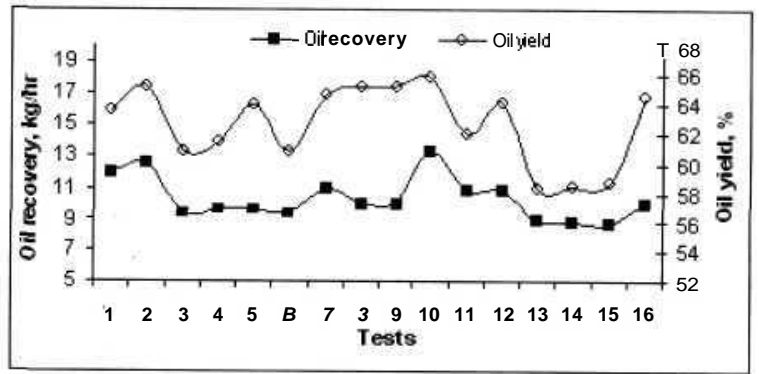

Figure 6. Oil yield and oil recovery of the expeller at field evaluation

Table 2. Quality analysis of coconut oil produced by the expeller

\begin{tabular}{|l|l|l|l|}
\hline \multicolumn{1}{|c|}{ Parameter } & \multicolumn{1}{c|}{ Lab test } & \multicolumn{1}{c|}{ Field test } & \multicolumn{1}{c|}{ SLS Standards } \\
\hline Free fatty acid & 0.04 & 0.05 & 0.2 max \\
\hline Colour & 0.1 Yellow, 0 Red & 0 Yellow, 0 Red & Y+5R not deeper than 1 \\
\hline Moisture & $0.10 \%$ & $0.12 \%$ & $0.2 \% \max$ \\
\hline Refractive index & 1.4485 & 1.1490 & $1.4480-1.4492$ \\
\hline Iodine value & 5.64 & 5.91 & $7.5-18.0$ \\
\hline
\end{tabular}

Coconut Research Institute analysis report (30.5.2006) 


\section{Conclusions}

The invented segmented-screw type expeller performed satisfactory oil extraction without generating heat with smooth movement of material through the screw barrel. Partially dried coconut was subjected to a shear and compression process, which lead to increase in oil yield. Oil produced by the expeller conformed to virgin quality grade.

The new arrangement of the screw shaft provides high pressure without clogging the material and it does not require sophisticated manufacturing technologies for fabrication. Since the expeller is operated by a 2HP singlephase motor, this can be introduced as a selfemployment project to produce virgin coconut oil at cottage level.

\section{Acknowledgements}

The author highly acknowledges the assistance given by Mr NADDJ Prasanna, Technical Assistant, throughout the study from fabricating several models to collecting required data while testing the expeller. Advice given by Eng HMLU Herath, Workshop Engineer, in machining of components is also acknowledged.

\section{References}

1. Anon, 2001. A new oil for the new millennium, Kokunut Pacific Pvt Ltd Explore 2000 in Hanover, Germany.

2. Anon, 2002. Specification for coconut oil (Second edition). Sri Lanka Standards 32;2002. Sri Lanka Standards Institute, Colombo.

3. Anon, 2003. Annual reports. Agriculture \& Post Harvest Technology Department, NERDC, Sri Lanka.

4. Anon, 2004. Central Bank Annual Report.

5. Anon, 2004. Screw design for co-rotating twinscrew extruders. Plastic Additive \& Compounding. Elsevier Ltd.

6. Bachmann, J., 2004. Oil seed processing for smallscale producers. ATTRA publication. National Center for Appropriate Technology, Fayettevile.

7. Enig, M.G., 1996. Health and nutritional benefits from coconut oil : An improvement functional food for the 21 Century. AVOC Lauvia Oils sympho sieve, Vietnam.
8. Fekete, R., Jasso, I., Peciar, M., Molnar, A., 2004. Influence of rotor on extrusion pressure. J. Powder Technology, 141, 210-218.

9. Gabriele, D., Curcio, S., Cindio, B., 2001. Optimal design of single screw extruder for liquorice candy production. Archeology based approach. J. Food Engineering, 48, 33-44.

10. Hilton, D.J., Etherington, D.M., 1997. Village scale system for production of high quality coconut oil. Australian National University, Australia.

11. Munoz, G., Gonsalez, M., Yanez, P., 2002. Extruder design to elaborate animal feed from crop residues. Technical library, ASAE.

12. Peiris, T.S.G., 2005. Sri Lankas are using more palm oils than coconut oil. Technical note, CRISL, Lunuwila.

13. Rantunge Y. M. M. K., 2001. Development of a virgin coconut oil expeller for house hold level oil extraction. Technical note, NERDC, Sri Lanka.

14. Senanayake, S.A.M.A.N. and Clarle, B,. 1999. A simplified twin screw co-rotating food extruder: design, fabrication and testing. J. Food Engineering, 40, 129-137.

15. Shantha, K.Y.H.D., 2004. Development of a hydraulic jack operated virgin coconut oil expeller. Technical note, NERDC, Sri Lanka 